\title{
Desain Kapal Penumpang Katamaran untuk Rute Dermaga Boom Marina, Banyuwangi - Pelabuhan Benoa
}

\author{
Mohammad Hamzah Satriawansyah dan Djauhar Manfaat \\ Jurusan Teknik Perkapalan, Fakultas Teknologi Kelautan, Institut Teknologi Sepuluh Nopember (ITS) \\ Jl. Arief Rahman Hakim, Surabaya 60111 Indonesia \\ e-mail: djauhar@na.its.ac.id
}

\begin{abstract}
Abstrak-Akhir tahun 2015, PT. Pelindo III (Persero) membangun Dermaga Boom Marina di Banyuwangi dan membuka rute pelayaran kapal Boom Marina Banyuwangi Pelabuhan Benoa Bali. Tujuan dari Penelitian ini adalah untuk mendesain sebuah kapal katamaran yang digunakan sebagai sarana penyeberangan dari Dermaga Boom Marina, Banyuwangi menuju Pelabuhan Benoa, Bali. Katamaran memiliki beberapa kelebihan jika dibandingkan dengan kapal monohull. Luas geladak dari katamaran lebih luas dibandingkan kapal monohull. Stabilitas kapal katamaran lebih baik dibandingkan kapal monohull. Sudut oleng pada kapal katamaran relative rendah sehingga meningkatkan rasa nyaman dan tidak mudah terkena mabuk laut. Dalam prosesnya desain kapal ini menggunakan parent design approach dengan mengacu pada suatu desain kapal pembanding yang sudah berlayar dengan baik. Proses desain ini mengacu pada kapal "Austal 48" sebagai kapal pembanding. Desain kapal ini juga turut diperhitungkan secara teknis maupun ekonomis. Ukuran utama kapal yang didapat adalah $\mathrm{Lwl}=44 \mathrm{~m}, \mathrm{~B}=11.8 \mathrm{~m}, \mathrm{~T}=1.4 \mathrm{~m}, \mathrm{H}$ $=3.8 \mathrm{~m}, B_{1}=3 \mathrm{~m}, C_{B}=0.491$, dan Vs $=28$ knots. Dari ukuran utama tersebut kemudian dibuat gambar rencana garis dan gambar rencana umum dan safety plan. Biaya pembangunan kapal sebesar Rp 24.422.508.434,58.
\end{abstract}

Kata Kunci-Banyuwangi, Benoa, Kapal Penumpang, Katamaran, Parent Design Approach

\section{PENDAHULUAN}

$\mathrm{P}$ ANTAI Boom merupakan pantai yang sering digunakan sebagai tempat dalam perhelatan besar yang diadakan oleh Pemerintah Kabupaten Banyuwangi. Pantai ini juga menjadi destinasi wisata yang menarik baik dari dalam maupun luar negeri. Sementara itu sejak 12 September 2015 lalu Pantai Boom sedang dalam proses pembangunan oleh pemerintah menjadi dermaga kapal pesiar dan berganti nama menjadi Dermaga Boom Marina Banyuwangi yang diharapkan menjadi bagian dari jaringan marina dunia sekaligus untuk mempromosikan wisata bahari Indonesia di dunia Internasional. Sebelumnya Menteri Pariwisata telah meresmikan program peluncuran rencana pengembangan marina atau dermaga kapal pesiar di Pantai Boom Banyuwangi pada 11 September 2015. Pembangunan marina di kawasan Pantai Boom dilakukan BUMN PT. Pelindo III melalui anak usahanya yaitu PT. Pelindo Properti Indonesia dan Pemerintah Kabupaten Banyuwangi. Peluncuran proyek tersebut berarti penataan kawasan Pantai Boom juga dimulai. Proyek pengembangan marina tersebut akan dikoneksikan dengan Pantai Tanjung Benoa di Bali dan Labuan Bajo di Nusa Tenggara Timur. Dermaga Boom Marina Banyuwangi direncanakan dapat beroperasi pada pertengahan 2017.

Berdasarkan penjelasan diatas maka pada penelitian ini saya akan membuat concept design (desain awal) kapal katamaran sebagai sarana penyeberangan di Banyuwangi-Bali dari Dermaga Boom Marina Banyuwangi dan Pelabuhan Benoa Bali dengan tetap memerhatikan faktor keamanan, kenyamanan, efisiensi bahan bakar, kecepatan kapal, dan jangkauan pelayaran, serta sesuai dengan owner requirement. Kapal jenis katamaran merupakan kapal memiliki dua lambung atau badan yang dihubungkan oleh geladak ditengahnya. Katamaran mempunyai geladak yang lebih luas dibandingkan dengan kapal monohull. Selain itu kapal katamaran juga mempunyai stabilitas yang lebih baik sehingga lebih nyaman digunakan dan juga memiliki hambatan gesek yang rendah sehingga dengan kekuatan dorong yang sama kecepatan yang dicapai dapat lebih tinggi.

\section{TINJAUAN PUSTAKA}

\section{A. Katamaran}

Katamaran merupakan kapal yang mempunyai dua lambung tau badan yang dihubungkan oleh geladak atau bridging platform ditengahnya. Bridging platform ini bebas dari permukaan air, sehingga slamming dan deck wetness kapal dapat dikurangi. Penentuan ketinggian struktur bagian atas dari permukaan air merupakan fungsi dari tinggi gelombang rute pelayaran yang dilalui. Kombinasi luas geladak yang besar dan berat kapal kosong yang rendah membuat kapal katamaran dapat diandalkan untuk transportasi muatan antar kota maupun pariwisata. (RINA, 2004)

Karakter tahanan di air tenang tipe katamaran lebih besar dibandingkan dengan kapal monohull. Dominasi tahanan gesek mencapai 40\% dari tahanan total pada kecepatan rendah. Penurunan kecepatan akibat kondisi gelombang tinggi 
tidak dijumpai pada kasus katamaran. Kapal tipe ini dapat dioperasikan pada kecepatan relative tinggi dan masih mempunyai konsumsi bahan bakar yang dapat diterima secara ekonomis. Tahanan tambahan akibat gelombang pada kapal katamaran adalah kecil dan kualitas seakeeping relative bagus untuk beroperasi pada kecepatan cepat antara 25-40 knots. (Wijnolst, 1996) [8]

\section{B. Metode Desain Kapal}

Metode Parent Design Approach merupakan salah satu metode dalam mendesain kapal dengan cara perbandingan atau komparasi dengan mengambil sebuah desain kapal pembanding sebagai acuan yang memiliki karakteristik yang sama dengan kapal yang akan didesain.

Langkah-langkah untuk menentukan ukuran utama kapal dengan metode Parent Design Approach sangat sederhana dan hal tersebut merupakan salah satu keuntungan dari metode ini yang dapat mempercepat proses mendesain. Dalam hal ini desainer sudah memiliki referensi kapal yang sama dengan kapal yang akan didesain, sehingga proses mendesain dapat lebih cepat dan hanya menambahkan beberapa modifikasi sesuai dengan owner requirements.

\section{Penentuan Ukuran Utama Kapal}

Ukuran utama kapal katamaran didapatkan dari metode Parent Design Approach dengan mengacu pada kapal pembanding. Ukuran utama yang didapatkan adalah sebagai berikut :

1. LOA (Length Overall) adalah panjang kapal keseluruhan yang diukur dari ujung buritan sampai ujung haluan.

2. Lwl (Length of Waterline) adalah panjang kapal yang diukur pasda garis sarat kapal.

3. B (Breadth) adalah jarak medatar dari gading tengah yang diukur pada bagian luar gading, dan tidak termasuk pelat lambung.

4. S (Beam Between Hull Centers) adalahjarak anatar kedua garis tengah (center line) dari masing-masing lambung.

5. BI (Beam of Each Hull) adalah lebar maksmum dari setiap lambung.

6. H (Height) adalah jarak vertikal yang diukur dari baseline sampai garis geladak.

\section{METODOLOGI PENELITIAN}

Metodologi dalam pengerjaan penelitian ini digambar dalam diagram alir (flow chart) pada Gambar III.1. berikut:

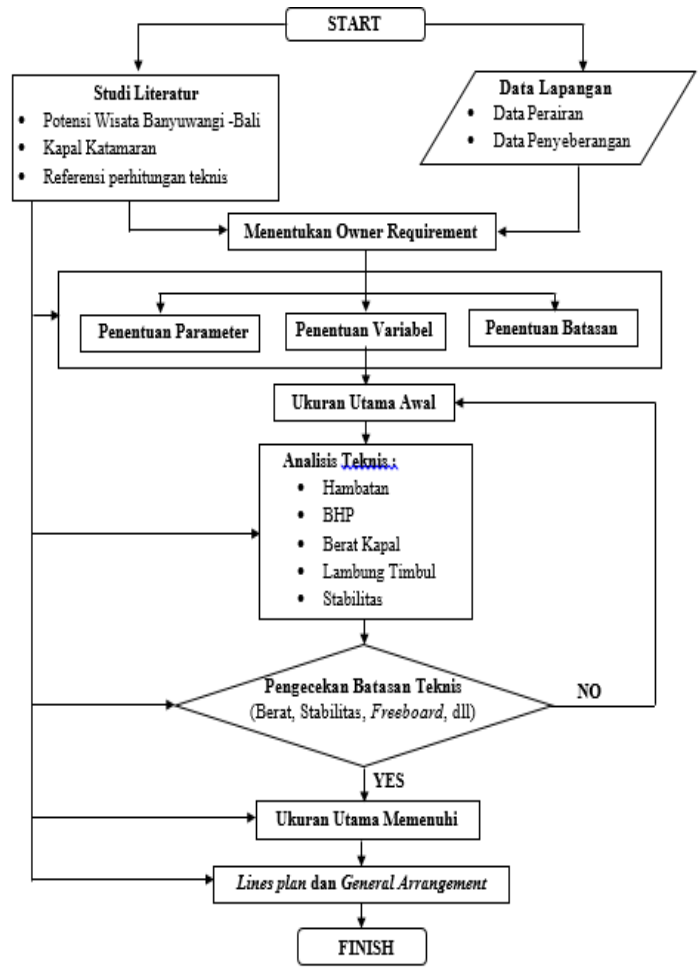

Gambar III.1. Diagram Alir Metode Pengerjaan

\section{TINJAUAN DAERAH}

\section{A. Tinjauan Umum}

Relief dan topografi Pulau Bali di tengah-tengah terbentang pegunungan yang memanjang dari barat ke timur. Provinsi Bali terletak diantara Pulau Jawa dan Pulau Lombok dengan batas wilayah sebagai berikut:

- Sebelah utara adalah Laut Bali

- Sebelah timur adalah Selat Lombok (NTB)

- Sebelah selatan adalah Samudera Indonesia

- Sebelah barat adalah Selat Bali (Jawa Timur)

Provinsi Bali sendiri memiliki luas wilayah sebesar 5.636,66 km² dengan garis pantai mencapai $529 \mathrm{~km}$ dan dibagi menjadi 8 Kabupaten.

Berdasarkan website resmi pemerintah Kabupaten Banyuwangi (www.banyuwangikab.go.id), Kabupaten Banyuwangi memiliki luas wilayah sebesar 5.782,5 $\mathrm{km}^{2}$ dengan panjang garis pantai sekitar 175,8 km. Kabupaten ini terletak di ujung timur selatan dari Provinsi Jawa Timur. Batas wilayah Kabupaten Banyuwangi antara lain sebagai berikut:

- Sebelah utara berbatasan dengan Kab. Situbondo

- Sebelah timur adalah Selat Bali

- Sebelah selatan adalah Samudera Hindia

- Sebelah Barat berbatasan dengan Kab. Jember dan Kab. Bondowoso 


\section{B. Rute Pelayaran}

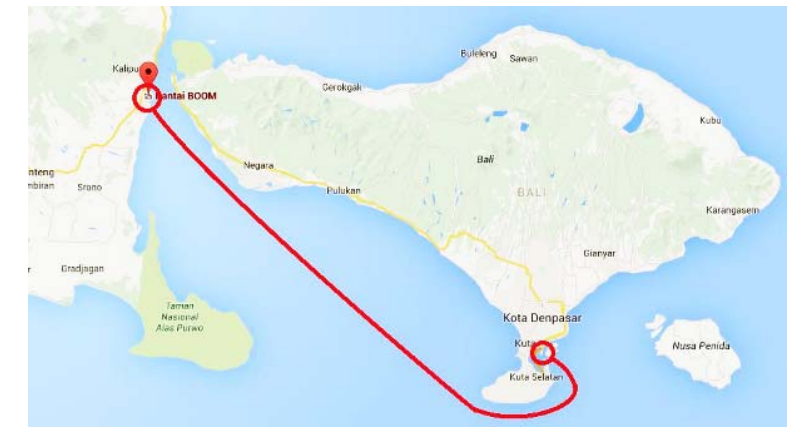

Gambar IV.1. Rute Pelayaran kapal penumpang katamaran

Dari gambar di atas menunjukkan rute pelayaran dari kapal penumpang katamaran. Jalur pelayaran yang direncanakan diawali dari titik pemberangkatan di Dermaga Boom Marina di Banyuwangi, kemudian melanjutkan perjalanan melalui Selat Bali dan mengitari Pulau Bali bagian selatan hingga sampai di Pelabuhan Benoa. Pada Tabel IV.1 akan disajikan data mengenai jarak antara Dermaga Boom Marina Banyuwangi menuju Pelabuhan Benoa melalui Selat Bali beserta waktu tempuh untuk mencapai ke Pelabuhan Benoa dengan kecepatan dinas kapal 28 knot. Jarak pelayaran didapatkan dengan menghitung jarak pada peta untuk mendapat jarak sesungguhnya.

\begin{tabular}{|c|c|c|c|c|}
\hline Berangkat & Tujuan & Jarak (km) & $\begin{array}{c}\text { Kecepatan } \\
\text { (knot) }\end{array}$ & $\begin{array}{l}\text { Waktu Tempuh } \\
\text { (menit) }\end{array}$ \\
\hline $\begin{array}{c}\text { Dermaga Boom } \\
\text { Marina }\end{array}$ & Pelabuhan Benoa & 145 & 28 & 167 \\
\hline $\begin{array}{c}\text { Pelabuhan } \\
\text { Benoa }\end{array}$ & $\begin{array}{c}\text { Dermaga Boom } \\
\text { Marina }\end{array}$ & 145 & 28 & 167 \\
\hline \multicolumn{5}{|c|}{ Jarak tempuh $=80 \mathrm{~nm}=145 \mathrm{~km}$ (google earth) } \\
\hline \multicolumn{5}{|c|}{ Dengan kecepatan kapal $28 \mathrm{Knot}=32.2 \mathrm{~nm} / \mathrm{jam}=51.9 \mathrm{~km} / \mathrm{jam}$} \\
\hline \multicolumn{5}{|c|}{ Waktu tempuh $=167$ menit $=2$ jam 47 menit } \\
\hline
\end{tabular}

Dari data di atas, dapat diketahui bahwa dengan kecepatan 28 knot kapal dapat berlayar dari Dermaga Boom Marina, Banyuwangi menuju Pelabuhan Benoa, Bali selama 2 jam 47 menit. Untuk rute sebaliknya dari Pelabuhan Benoa, Bali menuju Dermaga Boom Marina, Banyuwangi dianggap sama karena memiliki jarak yang sama dengan kecepatan yang sama. Jadi total lama perjalanan kapal untuk satu kali trip (Pulang Pergi) selama 334 menit atau 5 jam 34 menit.

Rencana jadwal pemberangkatan direncanakan 1 kali trip pulang pergi (Boom-Benoa-Boom) dalam satu hari. Dalam perencanaan tidak dilakukan perjalanan pada petang hari karena pertimbangan keselamatan dan visibilitas yang kurang. Lama satu kali perjalanan (Boom-Benoa) selama 2 jam 47 menit dibulatkan keatas menjadi 3 jam perjalanan.

\section{Analisis Jumlah Penumpang}

Dermaga Boom Marina Banyuwangi merupakan dermaga baru yang mulai dibangun pada akhir tahun 2015 dan diharapkan dapat mulai beroperasi pada pertengahan tahun 2017. Pembangunan tersebut dipegang oleh anak perusahaan dari PT. Pelindo III (Persero) yaitu PT. Pelindo Properti Indonesia. Dengan dibangunnya dermaga baru tersebut, PT. Pelindo III (Persero) membuka rute pelayaran baru yaitu Banyuwangi-Benoa dan Banyuwangi-Mataram.

Hingga saat ini penyeberangan Banyuwangi-Bali yang paling besar ada di penyeberangan ASDP KetapangGilimanuk. Dikarenakan rute pelayaran baru BanyuwangiBenoa belum beroperasi, maka diambil data penyeberangan Banyuwangi-Bali melalui ASDP Ketapang-Gilimanuk untuk analisis jumlah penumpang.

Tabel IV.2. Data Penyeberangan Ketapang-Gilimanuk Tahun 201 .
\begin{tabular}{|c|c|c|}
\hline Bulan & Trip & Jumlah Penumpang \\
\hline Januari & 7315 & 410796 \\
\hline Februari & 6879 & 315680 \\
\hline Maret & 6848 & 389628 \\
\hline April & 7108 & 364372 \\
\hline Mei & 7669 & 422292 \\
\hline Juni & 6974 & 344647 \\
\hline Juli & 7716 & 659223 \\
\hline Agustus & 7532 & 429462 \\
\hline September & 7238 & 348399 \\
\hline Oktober & 6911 & 386304 \\
\hline November & 5801 & 345670 \\
\hline Desember & 6991 & 534895 \\
\hline Total & 84982 & 4951368 \\
\hline
\end{tabular}

Dari data yang didapat dari PT. ASDP Indonesia Ferry Ketapang (Persero) pada Tabel IV.2. diambil data penyeberangan tahun 2015 agar perbandingan rata-rata penumpang tiap kapal tiap harinya sesuai dengan kondisi penyeberangan terkini. [2]

\section{DESAIN KAPAL PENUMPANG KATAMARAN}

\section{A. Penentuan Design Requirements}

Design requirement dalam Tugas Akhir ini adalah kapasitas penumpang, kecepatan kapal, dan rute pelayaran. Dari data yang disajikan diatas, didapat nilai rata-rata penyeberangan per hari per kapal sebanyak 388 penumpang. Jumlah tersebut didapat dengan pembagian rata-rata penumpang tiap harinya untuk 35 armada kapal. Kemudian penulis membulatkan jumlah penumpang menjadi 400 penumpang sebagai payload kapal, dengan berat bagasi setiap penumpang sebesar 20 kilogram.

\section{B. Penentuan Ukuran Utama Katamaran}

Pada Tugas Akhir ini ukuran utama ditentukan berdasarkan metode Parent Design Approach. Metode ini menggunakan suatu desain kapal pembanding yang sudah berlayar dengan baik sebagai acuan utama. Pemilihan kapal pembanding juga mempertimbangkan kondisi perairan rute pelayarannya, 
sehingga aspek kenyamanan juga tidak luput untuk dipertimbangkan. Output dari metode desain ini adalah mendapatkan suatu desain baru dari kapal pembanding (sister ship). Data kapal yang digunakan sebagai kapal pembanding adalah kapal katamaran "Austal 48” yang beroperasi di Hong Kong-Macau. Data teknis dari kapal pembanding dapat dilihat di bawah ini. [3]

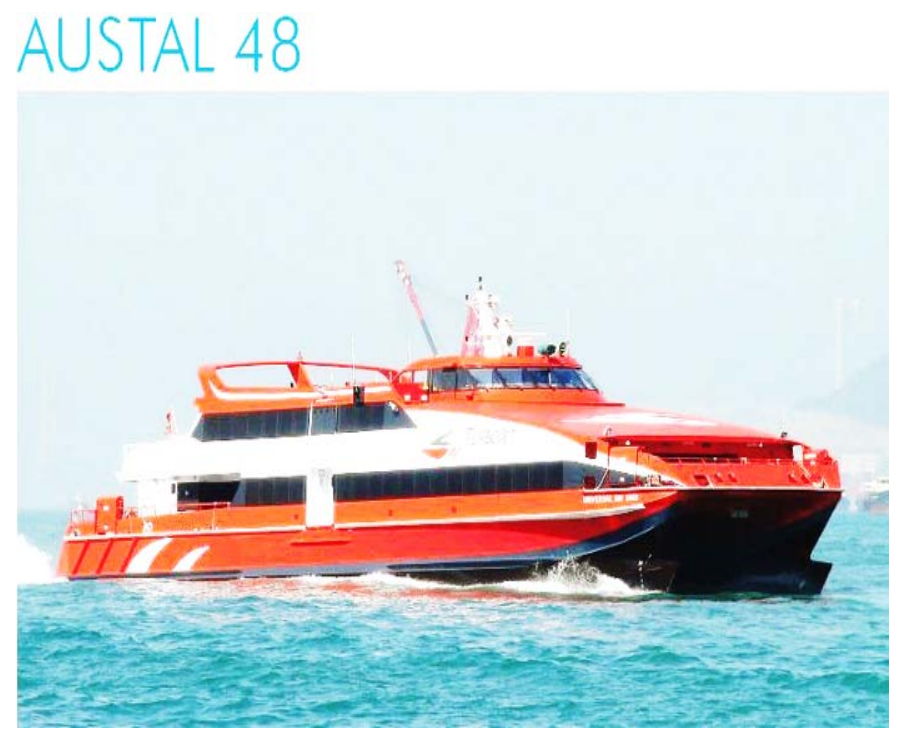

Gambar V.1. Kapal penumpang katamaran “Austal 48”

Ukuran kapal “Austal 48” adalah sebagai berikut:
a. $\mathrm{Lwl}=44.0 \mathrm{~m}$
b. $\mathrm{B}=11.8 \quad \mathrm{~m}$
c. $\mathrm{H}=3.8 \quad \mathrm{~m}$
d. $\mathrm{T}=1.4 \quad \mathrm{~m}$
e. $\mathrm{Vs}=41.1$ Knot
f. Passangers $=418$
g. Crew $=8$

Batasan rasio ukuran utama kapal didapatkan dari studi literature dan kapal-kapal katamaran yang sudah ada sekarang. Batasan kapasitas ditentukan berdasarkan prosentase dari selisih displacement kapal dengan jumlah LWT dan DWT agar bisa mengapung sesuai hukum Archimedes. Sedangkan batasan stabilitas ditentukan berdasarkan regulasi yang dikeluarkan oleh IMO A.749 (18) Chapter 3 dan HSC Code 2000 Annex 7. [4] [1]

Adapun batasan-batasan (constraints) tersebut adalah sebagai berikut:

Tabel V.1. Batasan perbandingan ukuran utama kapal

\begin{tabular}{|l|c|c|c|c|c|}
\hline & Unit & Symbol & Min & Value & Max \\
\hline $\mathrm{L} / \mathrm{B}_{1}$ & - & - & 10 & & 15 \\
\hline $\mathrm{B} / \mathrm{H}$ & - & - & 0.7 & & 4.1 \\
\hline $\mathrm{S} / \mathrm{L}$ & - & - & 0.19 & & 0.51 \\
\hline $\mathrm{S} / \mathrm{B}_{1}$ & - & - & 0.9 & & 4.1 \\
\hline $\mathrm{B}_{1} / \mathrm{T}$ & - & - & 0.9 & & 3.1 \\
\hline $\mathrm{B}_{1} / \mathrm{B}$ & - & - & 0.17 & & 0.3 \\
\hline $\mathrm{CB}$ & - & - & 0.36 & & 0.59 \\
\hline
\end{tabular}

Tabel V.2. Batasan kapasitas sesuai Hukum Archimedes

\begin{tabular}{|l|c|c|c|c|c|}
\hline & Unit & Symbol & Min & Value & Max \\
\hline Displacement $=2{ }^{*} \mathrm{~L}^{*} \mathrm{~B}^{*} \mathrm{~T}^{*} \rho$ & $\mathrm{kg}$ & $\Delta$ & & 190000 & \\
\hline DWT & $\mathrm{kg}$ & & & 78799 & \\
\hline LWT & $\mathrm{kg}$ & & & 104306 & \\
\hline Displacement $=$ DWT + LWT & $\mathrm{kg}$ & $\Delta$ & & 183105 & \\
\hline Selisih Displacement & $\%$ & & 0 & 3.63 & 5 \\
\hline
\end{tabular}

Tabel V.3. Batasan stabilitas dan freeboard

\begin{tabular}{|l|l|c|c|}
\hline Perhitungan stabilitas & Area 0 to 30 & $\mathrm{~m} . \mathrm{rad}$ & 0,055 \\
\hline \multirow{5}{*}{} & Area 0 to 40 & $\mathrm{~m} . \mathrm{rad}$ & 0,090 \\
\cline { 2 - 4 } & Area 30 to 40 & $\mathrm{~m} . \mathrm{rad}$ & 0,030 \\
\cline { 2 - 4 } & Max GZ at 30 or greater & $\mathrm{m}$ & 0.200 \\
\cline { 2 - 4 } & Angle of maximum GZ & $\mathrm{deg}$ & 10.0 \\
\cline { 2 - 4 } & Initial GMt & $\mathrm{m}$ & 0.150 \\
\cline { 2 - 4 } & Passenger crowding & $\mathrm{deg}$ & 10.0 \\
\hline Freeboard & fs (Freeboard) & $\mathrm{cm}$ & 165.6 \\
\hline
\end{tabular}

Dengan mengacu pada ukuran utama kapal penumpang katamaran "Ausatal 48" didapatkan ukuran utama kapal penumpang katamaran baru:

- $\mathrm{L}=44.0 \mathrm{~m}$

- $\mathrm{B}=11.8 \mathrm{~m}$

- $\mathrm{H}=3.8 \mathrm{~m}$

- $\mathrm{T}=1.4 \mathrm{~m}$

- $\mathrm{B} 1=3.0 \mathrm{~m}$

- $\mathrm{Vs}=28$ knot

- $\mathrm{Cb}=0.491$

Kemudian ukuran utama kapal yang baru dimasukkan kedalam batasan rasio kapal katamaran sebagai berikut:

Tabel V.4. Perbandigan ukuran utama baru kedalam batassan rasio kapal katamaran [5] [7]

\begin{tabular}{|l|l|l|l|l|}
\hline & & Min & Value & Max \\
\hline L/B1 & Sahoo, Browne \& Salas (2004) & 10 & 14.97 & 15 \\
\hline B/H & Insel \& Molland (1992) & 0.7 & 3.105 & 4.1 \\
\hline S/L & Insel \& Molland (1992) & 0.19 & 0.196 & 0.51 \\
\hline S/B1 & Insel \& Molland (1992) & 0.9 & 2.933 & 4.1 \\
\hline B1/T & Insel \& Molland (1992) & 0.9 & 2.143 & 3.1 \\
\hline B1/B & Multi Hull Ships, hal. 61 & 0.15 & 0.254 & 0.3 \\
\hline CB & Insel \& Molland (1992) & 0.36 & 0.491 & 0.59 \\
\hline
\end{tabular}




\section{Pembuatan Rencana Garis, Rencana Umum dan Safety Plan}

Selanjutnya dilanjutkan dengan pembuatan rencana garis, rencana umum dan safety plan. Pembuatannya menggunakan bantuan software Maxsurf dan $C A D$ :

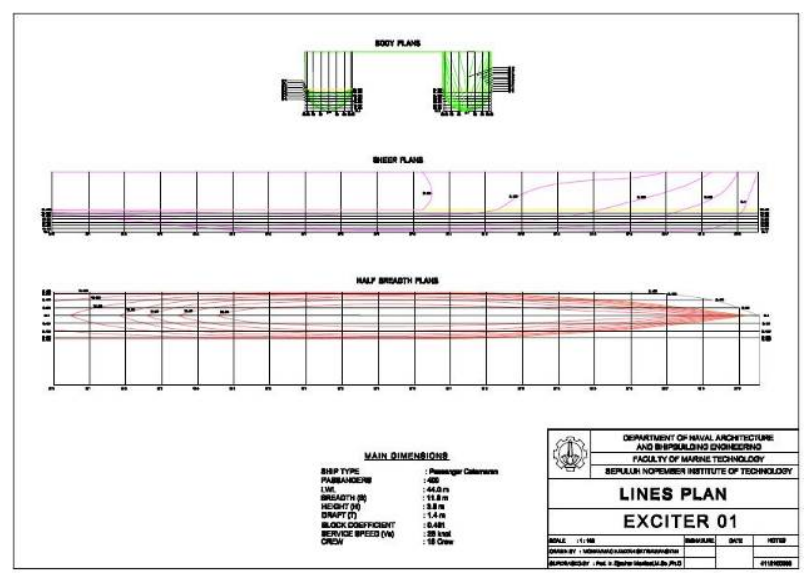

Gambar V.2. Rencana garis kapal penumpang katamaran

Proses pembuatan desain rencana umum dan safety plan dilakukan dengan memenuhi rules dan regulations yang berlaku dalam penempatan segala posisinya pada kapal [6]. Berikut hasil desain rencana umum dan safety plan kapal pada Gambar V.3. dan Gambar V.4:

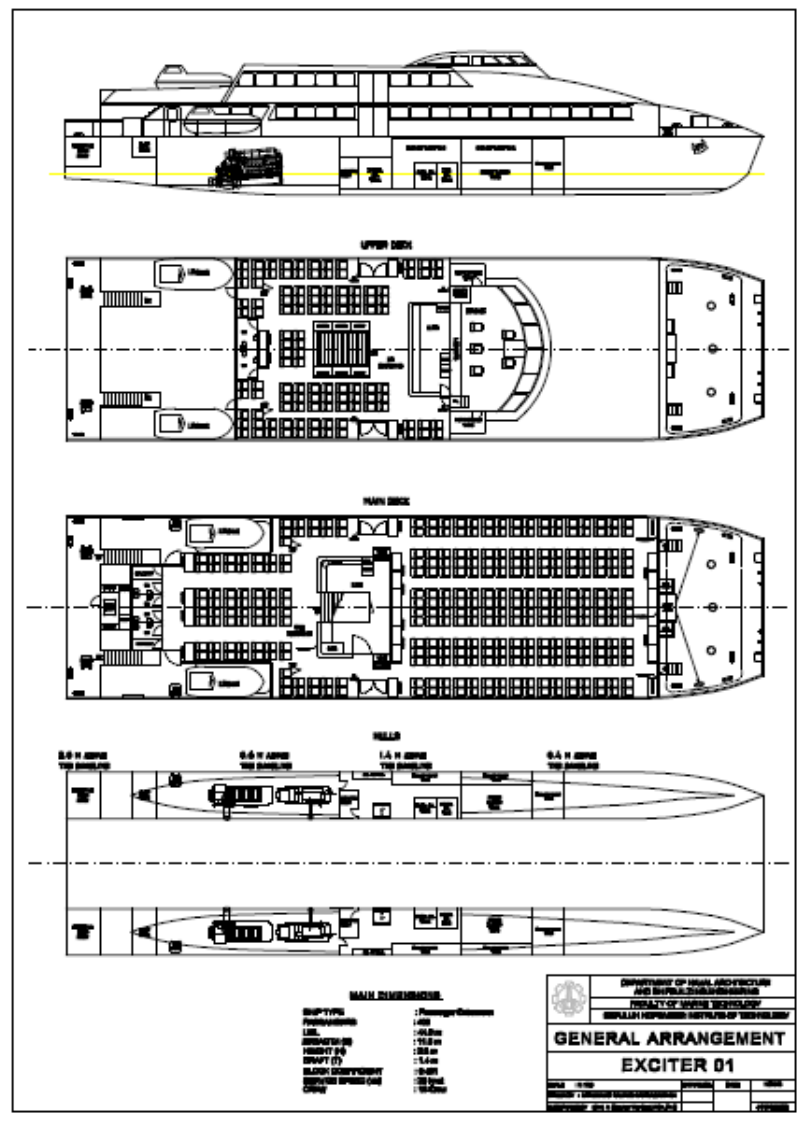

Gambar V.3. Rencana umum kapal penumpang katamaran

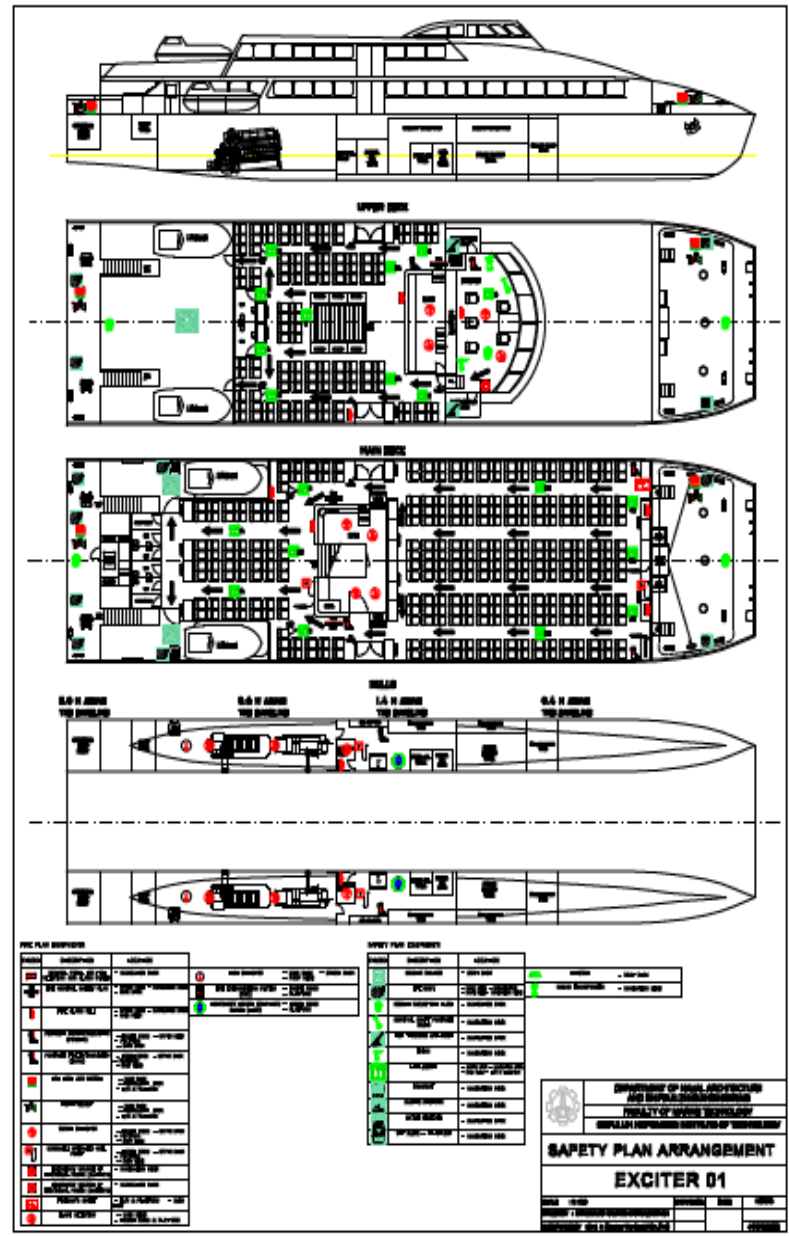

Gambar V.4. Safety plan kapal penumpang katamaran

\section{ANALISIS EKONOMIS}

Biaya pembangunan kapal terdiri dari beberapa komponen. Pada Tabel VI.1 dibawah ini akan dijelaskan mengenai perhitungan biaya pembangunan kapal.

Tabel VI.1. Rekapitulasi Perhitungan Biaya Pembangunan Kapal

\begin{tabular}{|c|l|c|c|}
\hline \multicolumn{2}{|c|}{ Biaya Pembangunan } & & \\
\hline No & Item & Value & Unit \\
\hline 1 & Pelat Kapal \& Elektroda & 50598 & USD \\
\hline 2 & Equipment \& Outfitting & 710574 & USD \\
\hline 3 & Tenaga Penggerak & $\mathbf{8 0 5 0 0 0}$ & USD \\
\hline \multicolumn{2}{|c|}{ Total Harga (USD) } & $\mathbf{1 5 6 6 1 7 2}$ & USD \\
\hline \multicolumn{2}{|c|}{ Kurs Rp - USD (per 16 Mei 2016, BD) } & 13328 & Rp/USD \\
\hline \multicolumn{2}{|c|}{ Total Harga (Rupiah) } & $\mathbf{2 0 , 8 7 3 , 9 3 8 , 8 3 2 . 9 7}$ & Rp \\
\hline
\end{tabular}

Dari perhitungan di atas dapat diketahui bahwa biaya pembangunan kapal adalah sebesar 1566172 USD atau Rp 20.873.938.832,97 dengan kurs yang didapat dari bank Indonesia per 16 Mei 2016 adalah 1 USD = Rp 13.328,Selanjutnya untuk menentukan harga jual kapal (price) maka harga pokok produksi akan dikoreksi terhadap keuntungan galangan, pajak, dan kondisi ekonomi. Perhitungan koreksi keadaan ekonomi dapat dilihat pada Table VI.2. 
Tabel VI.2 Perhitungan koreksi keadaan ekonomi pada biaya pembangunan kapal

\begin{tabular}{|c|l|c|c|}
\hline No & \multicolumn{1}{|c|}{ Item } & Value & Unit \\
\hline \multirow{2}{*}{$\mathbf{1}$} & Keuntungan Galangan & & \\
\cline { 2 - 4 } & $5 \%$ dari biaya pembangunan awal & & \\
\cline { 2 - 4 } & Keuntungan Galangan & $1,043,696,941.65$ & $\mathrm{Rp}$ \\
\hline \multirow{2}{*}{2} & Biaya Untuk Inflasi & & \\
\cline { 2 - 4 } & $2 \%$ dari biaya pembangunan awal & $417,478,776.66$ & $\mathrm{Rp}$ \\
\cline { 2 - 4 } & Biaya Inflasi & & \\
\hline \multirow{2}{*}{3} & Biaya Pajak Pemerintah & $2,087,393,883.30$ & $\mathrm{Rp}$ \\
\cline { 2 - 4 } & 10\% dari biaya pembangunan awal & $\mathbf{3 , 5 4 8 , 5 6 9 , 6 0 1 . 6 1}$ & $\mathbf{R p}$ \\
\cline { 2 - 4 } & Biaya Dukungan Pemerintah & & \\
\hline \multicolumn{2}{|c|}{ Total Biaya Koreksi Keadaan Ekonomi } \\
\hline \multirow{2}{*}{}
\end{tabular}

Biaya koreksi keadaan ekonomi terdiri dari 3 komponen, yaitu keuntungan galangan kapal, biaya untuk inflasi, dan pajak pemerintah. Dari perhitungan di atas didapatkan besarnya tiap komponen antara lain sebagai berikut :

$$
\begin{array}{ll}
\text { Keuntungan galangan } & =\mathrm{Rp} 1.043 .696 .941,65 \\
\text { Inflasi } & =\mathrm{Rp} \mathrm{417.478.776,66} \\
\text { Pajak } & =\mathrm{Rp} 2.087 .393 .883,30
\end{array}
$$

Maka, harga jual kapal (price) dapa dihitungan sebagai berikut :

Harga jual $($ price $)=$ Harga pokok produksi + Inflasi + Keuntungan Galangan + Pajak

Biaya pembangunan $=20.873 .938 .833+417.478 .777+$ 1.043.696.942+ 2.087.393.883

\section{$=\mathbf{R p} 24.422 .508 .434,58$}

\section{KESIMPULAN DAN SARAN}

Dari analisis, perhitungan teknis mengenai kapal penumpang katamaran yang beroperasi di Selat Bali, dapat ditarik kesimpulan sebagi berikut :

1. Didapatkan ukuran utama kapal, yaitu :
a. Lwl
$=44,0 \mathrm{~m}$
b. $\mathrm{B}$
$=11,8 \mathrm{~m}$
c. $\mathrm{B}_{1}$
$=3,0 \mathrm{~m}$
d. $\mathrm{H}$
$=3,8 \mathrm{~m}$
e. $\mathrm{T}$
$=0,491 \mathrm{~m}$
f. S
$=8,8 \mathrm{~m}$
g. Vs $=28$ knot
h. Crew $=18$ person
i. Passangers $=400$ person

2. Rencana garis dan rencana umum.

3. Dari analisis ekonomi yang sudah dilakukan, maka didapatkan hasil antara lain sebagai berikut :

$$
\begin{aligned}
& =\operatorname{Rp} 20.873 .938 .833,- \\
& =\operatorname{Rp} 24.422 .508 .435,- \\
& =\operatorname{Rp} 5.173 .955 .505,- \\
& =15 \% \\
& =\operatorname{Rp~3.730.538.163,-} \\
& =\operatorname{Rp} 21.430 .751 .151,-
\end{aligned}
$$$$
\text { - IRR }
$$

- Angsuran per tahun

Saran-saran yang dapat diberikan untuk pengembangan tugas akhir ini adalah sebagai berikut :
1. Perhitungan berat konstruksi agar dilakukan dengan lebih terperinci agar hasil yang didapatkan lebih akurat dan mendekati keadaan yang sebenarnya.

2. Perlu adanya pendalaman materi mengenai desain kapal berbahan aluminium karena didalam perkuliahan sebagian besar diajarkan desain kapal berbahan baja.

3. Perlu dilakukan pemeriksaan material konstruksi lebih lanjut untuk mengetahui kekuatan struktur konstruksi kapal.

4. Perlu dilakukan perhitungan biaya pembangunan kapal yang lebih akurat, seperti biaya tenaga kerja dan material yang digunakan dan waktu yang di butuhkan untuk pembangunan kapal.

\section{DAFTAR PUSTAKA}

[1] 2000 HSC Code. 2008. International Code of Safety for High-Speed Craft.

[2] ASDP Indonesia Ferry (Persero). 2016. Realisasi Angkutan Penyeberangan PT. ASDP Indonesia Ferry (Persero) Ketapang, Tahun 2015. Banyuwangi: PT. ASDP Indonesia Ferry (Persero) Ketapang.

[3] Austal. 2016. Austal 48401 \& 402. Diakses pada 2016, dari www.austal.com.

[4] International Maritime Organization (IMO). 2007. Revision of the Intact Stability Code.

[5] Molland, M., \& Insel, A. F. 1992. An Investigation Into the Resistance Components of High Speed Displacement Catamarans. RINA.

[6] Safety of Life at Sea (SOLAS) 1974/1978.

[7] Sahoo, P.K, Salas, M. \& Schwetz, A. 2007. Practical Evaluation of Resistance of High-Speed Catamaran Hull Forms-Part 1. Australia: Australia Maritime College.

[8] Wijnolst, Niko. 2008. Shipping Innovation. Amsterdam: Delft University Press. 